\title{
Border disease virus seroprevalence correlates to antibodies in bulk-tank milk and reproductive performance of dairy sheep flocks
}

\author{
A. L. García-Pérez, ${ }^{1}$ F. Ruiz-Fons, J. F. Barandika, G. Aduriz, R. A. Juste, and A. Hurtado \\ NEIKER-Instituto Vasco de Investigación y Desarrollo Agrario, Department of Animal Health, Berreaga 1, 48160 Derio (Bizkaia), Spain
}

\begin{abstract}
There is a great need to establish effective tools to control border disease virus (BDV) in European dairy sheep flocks. Hence, our main aim was to investigate the accuracy of analyzing anti-BDV antibodies in bulk-tank milk (BTM) in detecting the real BDV seroprevalence in dairy sheep flocks. Furthermore, the relevance of BDV to reproductive performance of dairy sheep flocks prompted us to search for the association between BDV seroprevalence and reproductive parameters. For these purposes, 34 flocks were selected based on different percentages of antibody inhibition (AIP) values in BTM as estimated by ELISA. Serum samples from 10 replacement lambs older than 6 mo, 10 ewes 1 to 2 yr old, and 10 ewes $>2$ yr old were collected and analyzed for the presence of anti-BDV antibodies by ELISA. A negative relationship between BDV AIP in BTM and withinflock seroprevalence was observed. Flocks with a high AIP $(>80 \%)$ had an average of $2.5 \%$ seropositive animals; flocks with a moderate AIP (46-79\%) had $11.4 \%$ seropositive animals; and finally, flocks with an AIP $\leq 45 \%$ showed a high flock seroprevalence $(57.2 \%)$. Ten out of 34 flocks showed a high BDV seroprevalence in lambs, suggesting the presence of persistently infected animals in the flock. The observed AIP values in BTM from these likely BDV-infected flocks were indicative of a high seroprevalence. The analysis of reproductiveparameters data collected from these flocks showed no differences in fertility or prolificacy in relation to BDV circulation rates. Nonetheless, lamb mortality was significantly greater in flocks with low-moderate seroprevalence (10-30\%), probably as a result of a firsttime contact with BDV of previously naïve ewes. These findings suggest that testing of BTM samples may be useful in inferring the BDV seroprevalence in a flock.
\end{abstract}

Key words: border disease, sheep, ELISA, bulk-tank milk

Received September 29, 2009.

Accepted February 9, 2010.

${ }^{1}$ Corresponding author: agarcia@neiker.net

\section{INTRODUCTION}

Border disease virus (BDV) is a worldwide distributed Pestivirus of sheep, closely related to bovine viral diarrhea virus and classical swine fever virus. Border disease virus is of great concern for sheep producers because of the problems it causes when infecting susceptible pregnant ewes (Hussin and Woldehiwet, 1994; Nettleton and Willoughby, 2007). Abortion, stillbirths, and unviable lambs are the main losses caused by infection with this pestivirus. The most relevant epidemiological feature of pestiviral infections is their ability to generate persistent infections. A persistent infection occurs when pregnant ewes are infected with BDV at the first stages of pregnancy. Infection during early embryonic and fetal development can lead to the birth of persistently infected (PI) animals that remain immunotolerant and seronegative for life and shed BDV in large quantities. Consequently, sheep in contact with PI animals quickly become infected and develop protective long-lasting neutralizing antibodies.

Identification and culling of PI animals has been identified as the target for the success of systematic nonvaccination control programs (Lindberg and Alenius, 1999). These programs have led to the eradication of pestiviruses from cattle in most of Scandinavia and other European regions (Lindberg and Alenius, 1999). In dairy cattle herds, control schemes consist of an initial analysis of bulk-tank milk (BTM) for the presence of antibodies against the virus, followed by testing of a selection of sera from first-lactation (2- to 3-yr-old) cows and nonlactating animals (Niskanen, 1993; Alenius et al., 1996; Beaudeau et al., 2001). These analyses allow one to infer the probability of having PI animals within the herd. A high viral seroprevalence in all age classes indicates a high probability of PI animals being present in the herd. In contrast, a positive result among the oldest lactating animals is strongly suggestive of absence of PI animals in the herd. Analysis of BTM is, hence, of great epidemiological relevance in dairy cattle herds, providing inexpensive valuable information on herd exposure to pestiviruses.

Border disease has been reported from several regions in Spain (Berriatua et al., 2004; Valdazo-González et al., 2006, 2007). Recently, our group estimated that 
$68 \%$ of dairy sheep flocks in our region (Basque Country, northern Spain) had been in contact with BDV (Berriatua et al., 2006) and identified BDV as one of the main causes of abortion in sheep (Oporto et al., 2006). In this scenario, BDV control schemes in dairy sheep flocks would be of great relevance. Therefore, to determine if control strategies similar to those proven successful for dairy cattle would be effective for sheep pestivirus control, we investigated the relationship between BDV antibody levels in sheep BTM and BDV flock seroprevalence. Considering the high relevance of BDV infection for sheep reproductive performance (Nettleton and Willoughby, 2007), the relationship between the BDV seroprevalence in sheep flocks and reproductive performance of the flocks was also evaluated within this study.

\section{MATERIALS AND METHODS}

\section{Study Design}

A total of 154 dairy sheep flocks belonging to the Selected Breeders Association from the Basque Country (northern Spain) were visited in March and April 2005 (see Berriatua et al., 2006, for further details). Briefly, a sample of BTM was collected per farm and analyzed for the presence of anti-BDV antibodies by means of a commercial ELISA test (Institute Pourquier, Montpellier, France) validated for bovine serum, plasma, and milk and ovine serum. Assuming a similar detection of antibodies between ovine and bovine BTM samples, the same standards established by the manufacturer for classifying the qualitative status of pestivirus in dairy cattle herds were used to classify sheep flocks. Hence, an antibody inhibition percentage (AIP) $<80 \%$ was considered indicative of a seropositive flock and negative otherwise.

To test whether BDV serological status of sheep flocks reflected by BTM sample analysis was representative of the real BDV seroprevalence in the flock, we selected sheep flocks with different AIP values in BTM. Thus, 34 flocks were selected, comprising 20 flocks with $\leq 45 \%$ AIP in BTM, 6 flocks with 46 to $79 \%$ AIP, and 8 flocks with $\geq 80 \%$ AIP in BTM. Each flock was revisited in autumn-winter 2005 before the next lambing season. Blood samples were then collected from 10 replacement lambs (6 mo to 1 yr old), 10 yearlings (1-2 yr old), and 10 adults ( $>2$ yr old) randomly selected from each of the 34 surveyed flocks. Serum was obtained after centrifugation of the collected blood and conserved at $-20^{\circ} \mathrm{C}$ until being analyzed.

\section{Serological Analyses}

Serum samples were used to detect anti-BDV p125/ p80 antibodies using a commercial blocking ELISA
(ELISA BVD-MD-BD P80 Anticorps, Institute Pourquier). The AIP of individual serum samples was calculated as

$$
\mathrm{AIP}=\mathrm{ODS} / \mathrm{ODN} \times 100
$$

where ODN = optical density of the negative control and ODS = optical density of the sample. Samples with an AIP value $\geq 50 \%$, ranging from 40 to $50 \%$, and $<40 \%$ were considered negative, weakly positive, and positive for BDV antibodies, respectively.

A flock was considered seropositive if the serum of at least one animal in the flock presented detectable levels of anti-BDV antibodies in the ELISA. We then calculated a mean BDV seroprevalence value for each of the surveyed flocks and for each age class (lambs, yearlings, and adults) within each flock. This value was calculated as the percentage of seropositive animals in the flock or age class in relation to the total number of animals analyzed in that flock.

Following criteria previously used in cattle (Thobokwe et al., 2004), we classified sheep flocks into 2 categories according to the level of seroprevalence in the replacement lamb age class: i) likely BDV-infected flocks ( $\geq 30 \%$ of lambs positive in the ELISA) and ii) likely BDV-noninfected flocks ( $<30 \%$ of lambs positive in the ELISA).

\section{Reproductive Data}

Reproductive data for the 2004-2005 breeding season were compiled from all except 4 flocks, which were excluded because of the low quality of reproductive data recorded by the farmers $(\mathrm{n}=30)$. Recorded data included fertility, prolificacy, lamb mortality, age at first lambing, and duration of the lambing period. Reproductive data were detailed for each of the age classes of sheep herein considered. In addition, the history of recent abortion (presence or absence of abortion during the 2004-2005 breeding season) was obtained from 30 of the 34 surveyed flocks.

\section{Statistical Analyses}

Differences on seroprevalence levels between age classes were assessed by ANOVA. The chi-squared test was used for comparison of the proportion of BDV seropositive lambs between likely infected and likely noninfected flocks. The relationship between BDV seroprevalence in the flock and BDV AIP values in BTM was evaluated by linear regression analysis (data log-transformed). To analyze the relationship between BDV seroprevalence and reproductive performance, linear regression analyses were performed separately 
Table 1. Individual data of border disease virus (BDV) seroprevalence in dairy sheep flocks and associated SE throughout age classes according to the antibody inhibition percentage (AIP) in bulk-tank milk (BTM) samples

\begin{tabular}{|c|c|c|c|c|c|c|c|c|c|}
\hline $\begin{array}{l}\text { BDV } \\
\text { AIP in } \\
\text { BTM }\end{array}$ & $\begin{array}{l}\text { No. of } \\
\text { flocks }\end{array}$ & \multicolumn{2}{|c|}{ Lambs $>6$ mo } & \multicolumn{2}{|r|}{ Ewes $1-2$ yr } & \multicolumn{2}{|r|}{ Ewes $>2$ yr } & \multicolumn{2}{|r|}{ Total } \\
\hline$\overline{46}-79 \%$ & 6 & 59 & $8(13.6 ; 0.04)$ & 56 & $1(1.8 ; 0.02)$ & 60 & $11(18.3 ; 0.05)$ & 175 & $20(11.4 ; 0.02)$ \\
\hline$\leq 45 \%$ & 20 & 196 & $78(39.8 ; 0.03)$ & 198 & $104(52.5 ; 0.04)$ & 202 & $159(78.7 ; 0.03)$ & 596 & $341(57.2 ; 0.02)$ \\
\hline$\overline{\text { Total }}$ & 34 & 334 & $86(25.7 ; 0.02)$ & 334 & $107(32.0 ; 0.03)$ & 343 & $174(50.7 ; 0.03)$ & 1,011 & $367(36.3 ; 0.02)$ \\
\hline
\end{tabular}

for the whole flock and for each age class. In a second approach, BDV flock seroprevalences were grouped into 3 different categories according to the level of BDV seroprevalence: low (0-10\%), medium (10-30\%), and high $(>30 \%)$. Then, associations between the categorized flock BDV seroprevalence and reproductive parameters were assessed by ANOVA. Again, analyses were performed separately for the whole flock and each age class as previously mentioned. The association between BDV flock seroprevalence and the presence or absence of abortion in the flock was assessed by the chi-squared test. Statistical uncertainty was assessed by calculating the $95 \%$ CI for each of the proportions according to the expression $\mathrm{SE}_{95 \% \mathrm{CI}}=1.96[\mathrm{p}(1-\mathrm{p}) / \mathrm{n}]^{1 / 2}$, where $\mathrm{p}=$ proportion and $\mathrm{n}=$ sample size (Martin et al., 1987). The SAS statistical package version 9.1 (SAS Institute Inc., Cary, NC) was used for statistical purposes.

\section{RESULTS}

\section{BDV Seroprevalence}

The results obtained from testing sheep sera by ELISA showed that $88.2 \pm 10.8 \%$ of the flocks $(30 / 34)$ and $36.3 \pm 3.0 \%$ of the animals $(367 / 1,011)$ had detectable level of antibodies against BDV. Replacement lambs showed lesser BDV seroprevalence $(25.7 \pm 4.6 \%)$ when compared with yearlings $(32.0 \pm 5.0 \%)$ and adult ewes $(50.7 \pm 5.4 \%)$, and these differences were statistically significant $(F=3.27, \mathrm{df}=2, P<0.05$; Table 1$)$.

Considering the percentage of seropositive lambs, 10 of the 34 flocks (29\%) were classified as likely BDV-infected flocks, and the remaining flocks $(71 \%)$ were clas- sified as likely BDV-noninfected flocks. The percentage of seropositive lambs in likely BDV-infected flocks was greater $(81.6 \pm 7.7 \%)$ than that in those classified as likely BDV-noninfected flocks $(2.5 \pm 2.0 \%$; Table 2$)$, and these differences were statistically significant $\left(\chi^{2}=\right.$ 78.6, $\mathrm{df}=1, P<0.001)$.

\section{BDV Seroprevalence and BTM AIP}

A statistically negative significant relationship $(\mathrm{r}=$ $-0.80 ; P<0.0001$; Figure 1) between BDV flock seroprevalence and BDV AIP in BTM was observed. Flocks with an AIP $\geq 80 \%$ in BTM had an average of $2.5 \pm$ $2.0 \%$ seropositive animals. Those flocks with moderate AIP (46-79\%) in BTM had an average of $11.4 \pm 4.7 \%$ seropositive animals. Finally, flocks with AIP $\leq 45 \%$ in BTM confirmed a high flock seroprevalence (57.2 \pm $4.0 \%$ ). Detailed information on BDV seroprevalence through age class for each of the previously mentioned categories of BDV AIP in BTM is provided in Table 1.

We found that those flocks classified as likely BDV infected had a mean AIP in BTM value of $20.1 \%$ (Table 2 ), which according to the guidelines provided by the manufacturer of the ELISA test used, is indicative of high seroprevalence. In contrast, likely BDV-noninfected flocks had a mean AIP value in BTM of $56.2 \%$, indicative of a moderate seroprevalence.

\section{BDV Seroprevalence and Reproductive Performance}

Animals from flocks with a previous history of abortion showed a significantly greater seroprevalence

Table 2. Data from dairy sheep flocks classified as likely border disease virus (BDV) infected or noninfected according to the level of BDV seroprevalence in the replacement lamb age class

\begin{tabular}{lcc}
\hline Item & $\begin{array}{c}\text { Likely BDV- } \\
\text { infected flocks }\end{array}$ & $\begin{array}{c}\text { Likely BDV- } \\
\text { noninfected flocks }\end{array}$ \\
\hline Flocks (no.) & 10 & 24 \\
Lambs analyzed (no.) & 98 & 236 \\
Seropositive lambs (no.) & 80 & 6 \\
Seropositive lambs, \% (SE) & $81.6(7.7)$ & $2.5(2.0)$ \\
Mean AIP in BTM ${ }^{1}(\%)$ & 20.1 & 56.2 \\
\hline
\end{tabular}

${ }^{1} \mathrm{AIP}=$ antibody inhibition percentage; BTM = bulk-tank milk. 


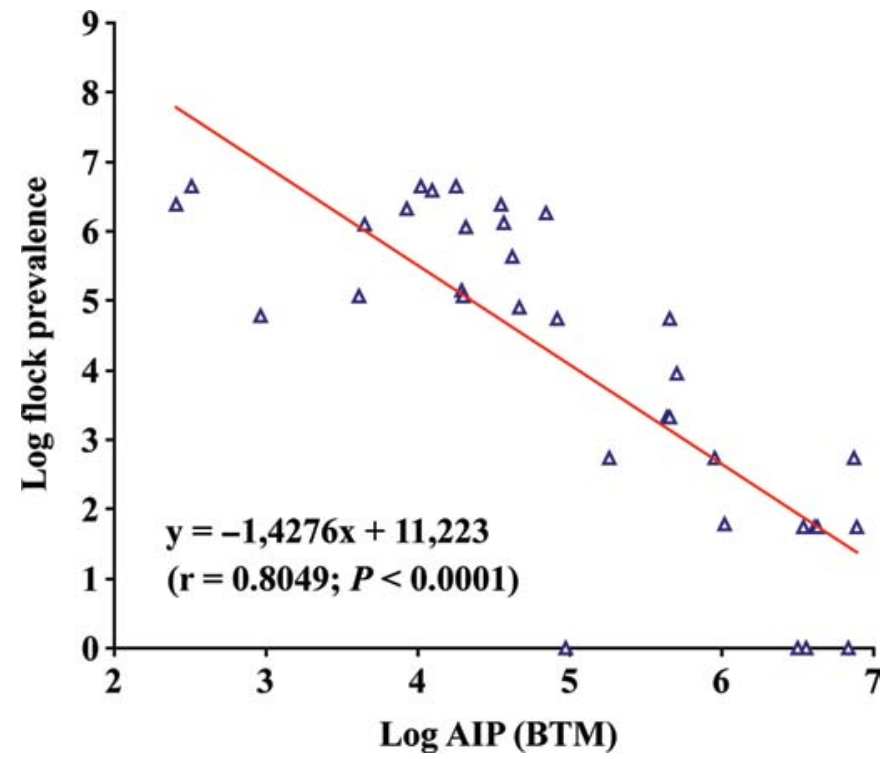

Figure 1. Scatterplot (open triangles) and trend line of bulk-tank milk (BTM) percentage inhibition (AIP) versus within-flock seroprevalence of border disease virus antibodies. Color version available in the online PDF

against BDV $(56.9 \pm 5.0 \%, 218 / 383)$ than that from flocks with nonreported abortion problems (18.3 \pm $3.4 \%, 93 / 508)\left(\chi^{2}=143.3, \mathrm{df}=1, P<0.0001\right)$.

No evidence of a statistically significant relationship between BDV seroprevalence levels in the flock and reproductive parameters was observed. Furthermore, no statistically significant relationship between BDV seroprevalence in lamb, yearling, and adult sheep and age-specific reproductive parameters was found.

Similarly, no statistically significant relationship between the categorized BDV seroprevalence $(<10 \%$, $10-30 \%,>30 \%)$ and fertility or prolificacy was observed (Table 3). However, the mortality of newborn lambs statistically differed between the categorized flocks for yearling animals $(F=5.1, \mathrm{df}=2, P<0.05)$ and for the whole flock $(F=3.9$, df $=2, P<0.05)$. Average lamb mortality $(12.0 \pm 2.7 \%)$ was particularly high in yearlings from flocks with low-moderate BDV seroprevalence (Figure 2, Table 3).

\section{DISCUSSION}

This research confirmed that serological testing of BTM samples is an effective tool to estimate the level of BDV seroprevalence in dairy sheep flocks, as previously reported for pestivirus in dairy cattle (Niskanen, 1993). Nevertheless, because blood sample collection was out of step with BTM collection, the culling of seropositive animals or the emergence of new recent infections during this time span could have biased the seroprevalence levels found in this study. In addition, despite being intended for bovine BTM samples, the ELISA test used herein was proven to be a reasonably accurate tool to test ovine BTM samples.

European dairy sheep breeds are mostly confined to Mediterranean countries. Sheep from these countries have been found to be infected by a wide diversity of pestivirus genotypes (Pratelli et al., 2001; Hurtado et al., 2003; De Mia et al., 2005; Thabti et al., 2005; Valdazo-González et al., 2007; Dubois et al., 2008; Oguzoglu et al., 2009). These results suggest that ELISA testing of BTM samples for BDV may be useful in helping control BDV in small ruminants in Mediterranean Europe. Bulk-tank milk analysis as an indication of flock BDV seroprevalence offers the possibility of largescale studies in dairy sheep populations. Furthermore, highly accurate information on BDV exposure and flock seroprevalence obtained by this methodology could be coupled with molecular techniques for genotype characterization (Berriatua et al., 2006).

Table 3. Mean reproductive parameters in the 2004-2005 reproductive season and their associated SE (within parentheses) for the border disease virus (BDV) seroprevalence categories $(0-10 \%, 10-30 \%,>30 \%)$ and age groups

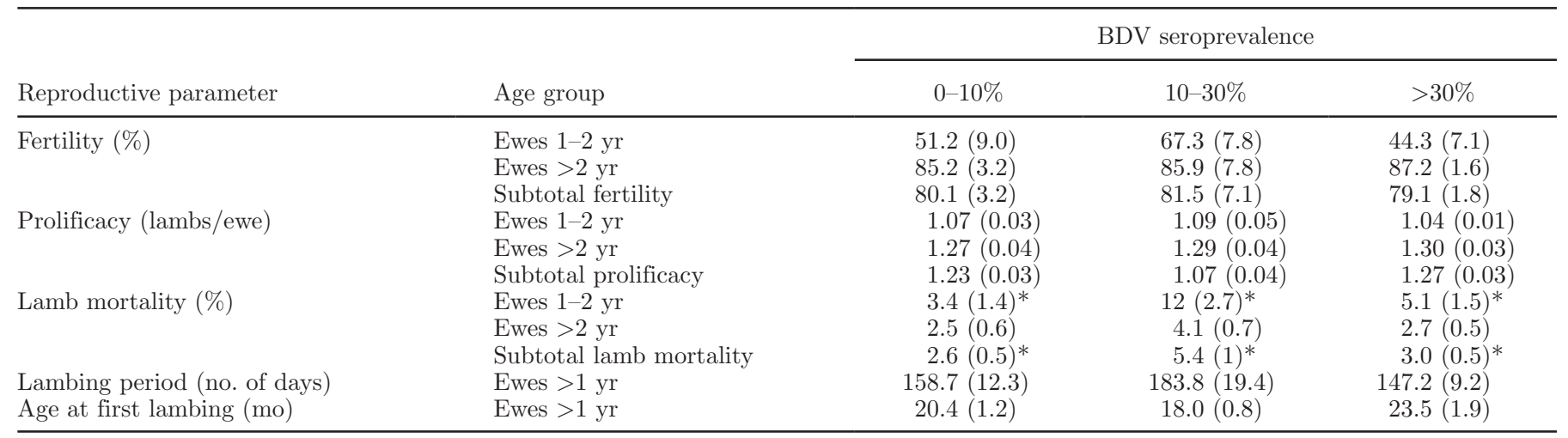

*Differences across BDV seroprevalence level are statistically significant. 


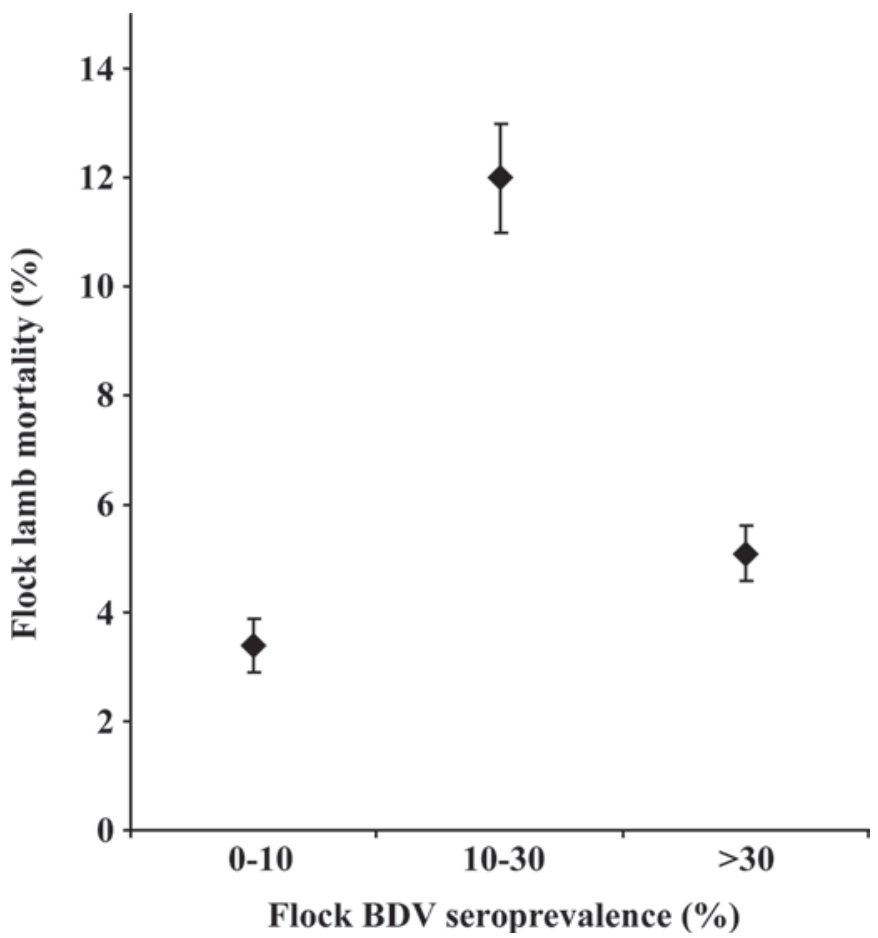

Figure 2. Percentage of lamb mortality in yearling ewes in 20042005 season in relation to the flock seroprevalence to border disease virus (BDV).

No vaccines have been commercialized in Europe for BDV control in small ruminants. Therefore, current BDV control strategies rely on the identification and culling of PI animals from the flock. Thus, after serological analysis of the whole flock, seronegative animals need to be tested by means of an antigen-ELISA (Berriatua et al., 2004). This is obviously an expensive strategy. As an example, the analysis of BDV antibody and antigen presence in a dairy flock with 250 ewes would cost around $€ 2,875$ using standard laboratory ELISA techniques; this would be the cost assuming a $70 \%$ seroprevalence (only $30 \%$ of the samples analyzed by antigen-ELISA). Alternatively, analyzing a combination of a single BTM sample and a reduced number of sera could be used as a relatively inexpensive first approach to evaluate the presence of PI animals in the flock. This is a widely used strategy in the control of bovine viral diarrhea virus in cattle, and studies based on just 5 to 10 blood samples accurately detected the presence of PI animals (Houe, 1992, 1994).

Border disease virus colostral antibodies tend to disappear by the age of 6 mo. The greater seroprevalence found in replacement lambs from 10 of the flocks studied herein was indicative of the presence of PI animals. In fact, the observed seroprevalence was comparable to that found in flocks with confirmed presence of PI animals (Berriatua et al., 2004). Situations with estimated seroprevalence $>30 \%$ based on AIP values in BTM but with a low BDV seroprevalence in replacement lambs would probably be the result of the removal of PI animals from the flock a few years earlier.

Several studies have estimated the economic effect of bovine viral diarrhea virus in dairy cattle herds (Houe, 1999; Heuer et al., 2007). In contrast, currently available information on the economic effect of BDV in sheep flocks is scarce and outdated (Sweasey et al., 1979; Sharp and Rawson, 1986). For this reason, potential associations between reproductive losses and within-flock BDV seroprevalence levels were investigated in this study. Lamb mortality was associated to low-moderate BDV seroprevalence, probably as a consequence of a recent entrance of the virus into the flock. Hence, BDV might have an effect on reproduction when the virus first enters the flock and ewes are not immune. These results are in agreement with observations after experimental infection of pregnant ewes with the most common BDV genotype circulating in Spain (GarcíaPérez et al., 2009). Unexpectedly, other reproductive indicators such as duration of the lambing period (longer when early fetal or embryo mortality occurs) or age at first lambing (older when abortion occurs) did not show any clear association with BDV seroprevalence. Our results provide interesting information on the deleterious effect of the circulation rate of BDV in sheep production. Nonetheless, we have to consider that in this region (Basque Country) farmers apply different reproductive management strategies to their sheep, which was not adequately evaluated with the low number of sheep flocks analyzed $(\mathrm{n}=30)$. Furthermore, the possible influence of other abortifacient pathogens in the observed reproductive patterns was impossible to evaluate. Preliminary analyses of the relationship between BDV seroprevalence and milk production in the studied flocks indicated no significant association (data not shown). However, indirect losses in milk production resulting from abortions associated with BDV infection should also be considered in dairy flocks.

In conclusion, considering the wide distribution of BDV in our study area (Berriatua et al., 2006; Oporto et al., 2006) and the associated reproductive losses reported herein, BDV might significantly contribute to high economic losses in sheep dairy flocks in northern Spain. The implementation of a large-scale control program based on serological studies of BTM and a small number of sera in each flock, including replacement lambs, could facilitate the detection of infected flocks and avoid the dissemination of BDV.

\section{ACKNOWLEDGMENTS}

This work was funded by Instituto Nacional de Investigación y Tecnología Agraria y Alimentaria (INIA, 
RTA04-057) and Departamento de Medio Ambiente, Planificación Territorial, Agricultura y Pesca (DAPA) from the Basque Government, Spain. The authors thank Josune Arranz and Ina Beltrán de Heredia from NEIKER-Arkaute for their effort in compiling and revising the productive database. Francisco Ruiz-Fons is supported by a postdoctoral grant of the Instituto de Salud Carlos III of the Spanish Ministry of Health.

\section{REFERENCES}

Alenius, S., A. Lindberg, and B. Larsson. 1997. A national approach to the control of bovine viral diarrhoea virus. Pages 162-169 in Proc. 3rd ESVV Symp. Pestivirus Infections, Lelystad, the Netherlands. S. Edwards, D. J. Paton, G. Wenswort, ed. CVL, Weybridge, UK.

Beaudeau, F., S. Assié, H. Seegers, C. Belloc, E. Sellal, and A. Joly. 2001. Assessing the within-herd prevalence of cows antibodypositive to bovine viral diarrhoea virus with a blocking ELISA on bulk tank milk. Vet. Rec. 149:236-240.

Berriatua, E., J. F. Barandika, G. Aduriz, R. Atxaerandio, J. Garrido, and A. L. García-Pérez. 2004. Age-specific seroprevalence of Border disease virus and presence of persistently infected sheep in Basque dairy-sheep flocks. Vet. J. 168:336-342.

Berriatua, E., J. F. Barandika, G. Aduriz, A. Hurtado, L. Estevez, R. Atxaerandio, and A. L. García-Pérez. 2006. Flock-prevalence of border disease virus infection in Basque dairy-sheep estimated by bulk-tank milk analysis. Vet. Microbiol. 118:37-46.

De Mia, G. M., I. Greiser-Wilke, F. Feliziani, M. Giammarioli, and A. De Giuseppe. 2005. Genetic characterization of a caprine pestivirus as the first member of a putative novel pestivirus subgroup. J. Vet. Med. B Infect. Dis. Vet. Public Health 52:206-210.

Dubois, E., P. Russo, M. Prigent, and R. Thiéry. 2008. Genetic characterization of ovine pestiviruses isolated in France, between 1985 and 2006. Vet. Microbiol. 130:69-79.

García-Pérez, A. L., E. Minguijón, L. Estévez, J. F. Barandika, G. Aduriz, R. A. Juste, and A. Hurtado. 2009. Clinical and laboratorial findings in pregnant ewes and their progeny infected with Border disease virus (BDV-4 genotype). Res. Vet. Sci. 86:345-352.

Heuer, C., A. Healy, and C. Zerbini. 2007. Economic effects of exposure to bovine viral diarrhea virus on dairy herds in New Zealand. J. Dairy Sci. 90:5428-5438.

Houe, H. 1992. Serological analysis of a small herd sample to predict presence or absence of animals persistently infected with bovine viral diarrhoea virus (BVDV) in dairy herds. Res. Vet. Sci. $53: 320-323$.

Houe, H. 1994. Bovine virus diarrhoea virus: Detection of Danish dairy herds with persistently infected animals by means of a screening test of ten young stock. Prev. Vet. Med. 19:241-248.
Houe, H. 1999. Epidemiological features and economical importance of bovine virus diarrhoea virus (BVDV) infections. Vet. Microbiol. 64:89-107.

Hurtado, A., A. L. García-Pérez, G. Aduriz, and R. A. Juste. 2003. Genetic diversity of ruminant pestiviruses from Spain. Virus Res. 92:67-73.

Hussin, A. A., and Z. Woldehiwet. 1994. Border disease virus: A review. Vet. Bull. 64:1131-1151

Lindberg, A. L., and S. Alenius. 1999. Principles for eradication of bovine viral diarrhoea virus (BVDV) infections in cattle populations. Vet. Microbiol. 64:197-222.

Martin, S. W., A. H. Meek, and P. Willeberg. 1987. Veterinary Epidemiology. Principles and Methods. 1st ed. Iowa State Univ. Press, Ames, IA.

Nettleton, P. F., and K. Willoughby. 2007. Border disease. Pages 119-126 in Diseases of Sheep. 4th ed. I. D. Aitken, ed. Blackwell Publishing, Oxford, UK.

Niskanen, R. 1993. Relationship between the levels of antibodies to bovine viral diarrhoea virus in bulk tank milk and the prevalence of cows exposed to the virus. Vet. Rec. 133:341-344.

Oguzoglu, T. C., M. T. Tan, N. Toplu, A. B. Demir, S. Bilge-Dagalp, T. Karaoglu, A. Ozkul, F. Alkan, I. Burgu, L. Haas, and I. GreiserWilke. 2009. Border disease virus (BDV) infections of small ruminants in Turkey: A new BDV subgroup? Vet. Microbiol. 135:374-379.

Oporto, B., J. F. Barandika, A. Hurtado, G. Aduriz, B. Moreno, and A. L. Garcia-Perez. 2006. Incidence of ovine abortion by Coxiella burnetii in northern Spain. Ann. N. Y. Acad. Sci. 1078:498-501.

Pratelli, A., V. Martella, F. Cirone, D. Buonavoglia, G. Elia, M. Tempesta, and C. Buonavoglia. 2001. Genomic characterization of pestiviruses isolated from lambs and kids in southern Italy. J. Virol. Methods 94:81-85.

Sharp, M. W., and B. C. Rawson. 1986. The cost of Border disease infection in a commercial flock. Vet. Rec. 119:128-130.

Sweasey, D., D. S. Patterson, C. Richardson, J. W. Harkness, I. G. Shaw, and W. W. Williams. 1979. Border disease: A sequential study of surviving lambs and an assessment of its effect on profitability. Vet. Rec. 104:447-450.

Thabti, F., C. Letellier, S. Hammami, M. Pépin, M. Ribière, A Mesplède, P. Kerkhofs, and P. Russo. 2005. Detection of a novel border disease virus subgroup in Tunisian sheep. Arch. Virol. 150:215-229.

Thobokwe, G., C. Heuer, and D. P. Hayes. 2004. Validation of a bulk tank milk antibody ELISA to detect dairy herds likely infected with bovine viral diarrhoea virus in New Zealand. N. Z. Vet. J. $52: 394-400$.

Valdazo-González, B., M. Alvarez-Martinez, and I. Greiser-Wilke. 2006. Genetic typing and prevalence of Border disease virus (BDV) in small ruminant flocks in Spain. Vet. Microbiol. 117:141-153.

Valdazo-González, B., M. Alvarez-Martinez, and T. Sandvik. 2007. Genetic and antigenic typing of border disease virus isolates in sheep from the Iberian Peninsula. Vet. J. 174:316-324. 